ARTIGO

ESPAÇO, ECONOMIA E POPULAÇÃO

\title{
O ESPAÇO E O LUGAR DAS CIDADES MÉDIAS NA REDE URBANA BRASILEIRA
}

\author{
Clauber Eduardo Marchezan Scherer ${ }^{1 a, b, c, d, e, f}$ \\ Pedro Vasconcelos Maia do Amaral ${ }^{1 a, b, c, d, e, f}$ \\ 1 Universidade Federal de Minas Gerais, Cedeplar, Belo Horizonte, MG, Brasil.
}

\begin{abstract}
Resumo
Partindo da hipótese de que o tamanho da população é um fator insuficiente para capturar a inserção dos centros urbanos nos diferentes níveis hierárquicos da rede de cidades, analisa-se o caso recente do Brasil-200o e 2010. É dado destaque para as categorias nas posições intermediárias da rede, as cidades médias, centros para os quais ainda se tem um conhecimento limitado sobre seu papel na rede brasileira. Para isso, utiliza-se a composição de empregos das cidades em setores-chaves e aplicam-se explorações empíricas que combinam técnicas de análise multivariadas baseada em agrupamentos. Como resultado, percebe-se uma continuidade da interiorização da rede - já constatada para recortes temporais anteriores -, porém com maior intensidade nas regiões Norte e Nordeste, onde houve aumento expressivo do número de centros urbanos nos níveis intermediários da rede, especialmente nos grupos que dizem respeito às cidades médias.

Palavras-chave

cidades médias; hierarquia urbana; centralidade; rede de cidades; Brasil.
\end{abstract}

\footnotetext{
a. fundamentação teórico-conceitual e problematização; b. pesquisa de dados e análise estatística; c. elaboração de figuras e tabelas; d. fotos; e. elaboração e redação do texto; f. seleção das referências bibliográficas.
} 
THE LOCATION AND THE PLACE OF MEDIUM SIZE CITIES IN THE BRAZILIAN CITIES NETWORK

\author{
Clauber Eduardo Marchezan Scherer ${ }^{1}$ \\ Pedro Vasconcelos Maia do Amaral ${ }^{1}$ \\ 1 Universidade Federal de Minas Gerais, Cedeplar, Belo Horizonte, MG, Brasil.
}

\begin{abstract}
Based on the hypothesis that population size is an insufficient factor to explain the role of urban centers in the different hierarchical levels of the city network, Brazil's case is analyzed for the period 2000-2010. Moreover, it is emphasizing categories in the intermediate positions of the network, the medium sized cities, centers for which there is still a limited knowledge about its function in the Brazilian network. To do that work, based on the composition of jobs of the cities in key sectors, empirical explorations are applied combining techniques of multivariate analysis based on clusters. As a result, it is possible to observe a continuity of the internalization of the network - already verified for previous temporal cuts - but with greater intensity in the North and Northeast regions, where the number of urban centers in the intermediate levels of the network was increased expressively, especially in groups related with medium-sized cities.

Keywords medium sized cities; urban hierarchy; centrality; network of cities; Brazil.
\end{abstract}




\title{
O ESPAÇO E O LUGAR DAS CIDADES MÉDIAS NA REDE URBANA BRASILEIRA
}

\author{
Clauber Eduardo Marchezan Scherer \\ Pedro Vasconcelos Maia do Amaral
}

\section{Introdução}

As cidades, como espaços de concentração tanto de firmas como de pessoas, são por excelência ambiente favorável para a geração de externalidades positivas advindas dessas aglomerações. Para as firmas, propiciam que estas se beneficiem não apenas de suas escalas internas, mas também das economias externas derivadas da concentração no espaço. Para as pessoas, permitem o acesso a uma variedade maior de produtos e facilitam a tarefa de encontrar atividades compatíveis com seus perfis.

No plano regional, as cidades constituem-se como elementos-chaves no processo de articulação e comando do espaço e podem ser consideradas a base e o elemento decisivo para o desenvolvimento regional e o ordenamento do território (BRASIL, 2008). Sua capacidade de articulação depende, sobretudo, da sua escala (tamanho), da natureza da sua base produtiva, de sua localização e da infraestrutura de transporte que ela desfruta.

Nesse contexto, pensar a região sem levar em conta o papel desempenhado pelos diferentes tipos de cidade que a compõem torna-se, no mínimo, exercício com alcance bastante limitado. Assim, ao abordar a questão regional brasileira recente, é fundamental que se levem em conta as cidades como elemento de articulação e transformação local, em especial as médias, que, ao cumprirem funções de intermediação entre os grandes núcleos urbanos metropolitanos e as pequenas cidades e o meio rural, têm destacado papel como fator de balanceamento da rede urbana. 
Tais questionamentos ganham maior relevância quando se observa que boa parte dos trabalhos empíricos desenvolvidos, e que utilizam a ideia de cidades médias, parte do critério demográfico/populacional como elemento definidor da classe, de maneira que uma reflexão mais aguçada do tema esbarra na inexistência de parâmetros capazes de estabelecer e avaliar essa categoria de centros. A partir disso, é imediato questionar: quais são e onde se encontram as cidades médias brasileiras? Ainda: quais características e funções dessas cidades são identificadas como elos importantes na articulação da rede e, em última instância, na formatação de um processo de desenvolvimento regional consistente?

Assim, acredita-se que, para uma avaliação mais robusta em torno do tema, é preciso agregar ao tamanho populacional outros elementos que consigam capturar a forma de inserção dessas cidades na rede e, mais especificamente, fatores que lhes conferem a propriedade de ser uma cidade média. Essa investigação é importante, sobretudo em um caso como o do Brasil, onde a assimetria entre as cidades grandes e pequenas é bastante notável em função da expressiva heterogeneidade regional existente, de modo que uma cidade de 100 mil habitantes em São Paulo, por exemplo, tem uma inserção distinta de uma com mesmo tamanho no estado de Roraima.

Nesse sentido, parte-se da hipótese de que as atividades desenvolvidas em uma cidade, tanto por meio da maior oferta de serviços específicos nesses lugares (CHIRSTALLER, 1966; LÖSCH, 1954) como por meio de sua capacidade de criação de economias de aglomeração, advindas da especialização/diversificação (MARSHALL, 1890; JACOBS, 1969), são elementos que conseguem captar a dinâmica desses locais. Desse modo, aqui se assume que a distribuição setorial dos empregos em setores-chave seja capaz de apresentar um retrato importante da inserção das cidades dentro da rede.

Com base nisso, para a identificação e a caracterização da rede urbana, buscando nela os grupamentos associados às cidades médias em 2000 e 2010, foram empregadas metodologias de análise de aglomerados - clusters -, com a identificação de grupamentos que, em função de suas características semelhantes, possam ser utilizados como ponto de partida para uma análise mais refinada acerca das cidades médias e suas singularidades nos diferentes contextos regionais em que estão inseridas.

Além dessa introdução, o trabalho está organizado em mais quatro seções. Inicialmente é feita uma breve explanação sobre a evolução da rede urbana brasileira e, a partir disso, explora-se o modo como emerge a necessidade de compreensão das cidades médias. Posteriormente, apresentam-se a metodologia e a base de dados utilizada no trabalho, para, ao final, demonstrar os resultados da pesquisa e tecer as considerações finais. 


\section{Justificativa}

O rápido e acelerado processo de urbanização pelo qual passou o Brasil lhe confere singularidade reservada a poucas nações na história mundial. Analisando os dados censitários, percebe-se que, em um período de sessenta anos, o país saiu de um quadro em que $36,16 \%$ da população era urbana para uma realidade em que, em 2010, aproximadamente 84,36\% vivia nessa situação.

Dentre as mais variadas facetas desse processo, destaca-se aqui o que se entende por uma de suas consequências mais importantes: uma notável reestruturação da rede urbana do país, refletida tanto no tamanho de suas cidades como nas relações de interdependência entre elas. Esse processo tem importantes impactos na dinâmica regional do Brasil e acaba por dar novo significado à questão das cidades médias. Vêm daí a necessidade e a importância de compreender esses centros.

\subsection{Evolução da rede de cidades brasileira}

Diretamente ligados à urbanização, dois fatores destacaram-se na criação de condições para o surgimento e a consolidação de novos centros dinâmicos no país: (i) a industrialização, que, beneficiando-se da evolução e do melhoramento das tecnologias de telecomunicação e das redes de transportes no país, a partir do início dos anos 1980 levou a um "espraiamento concentrado" do parque industrial (DINIZ, 1993);" (ii) a ocupação das áreas de fronteira em direção às regiões Norte e Centro-Oeste, guiadas pelas atividades agropecuárias e extrativas (Ipea/IBGE/Unicamp, 2001).

Esses são fatores importantes no processo de articulação territorial do Brasil, de modo que, se até a década de 1950 a rede era esparsa e desarticulada, concentrada em faixas litorâneas fortemente ligadas às heranças históricas primário-exportadoras, inaugura-se a partir de então um período marcado por novos contornos e conectividades para a sua rede de cidades (BECKER; EGLER, 1994). Assim, ao mesmo tempo que amadurece a rede, ampliam-se as articulações entre as cidades e as regiões, levando com isso a um notável aumento da complexidade de seus padrões espaciais (CORRÊA, 2007).

Mais que isso, em decorrência do movimento de interiorização do país, é impulsionada a emergência de centros urbanos intermediários, modificando assim as áreas polarizadas pelas cidades. Consequentemente, provocam-se alterações na rede urbana como um todo, estimulando o surgimento e a consolidação de novas regiões dinâmicas, as quais são polarizadas, sobretudo, por cidades médias (SIMÕES; AMARAL, 2011).

1 Existe ampla literatura que trata do espalhamento/concentração - e controvérsias envolvidas - da indústria brasileira sob uma perspectiva regional. Para uma síntese, ver Sobrinho e Azzoni (2016). 
Nesse cenário de mudanças espaciais, na década de 1970, no II Plano Nacional de Desenvolvimento, pela primeira vez uma política de desenvolvimento urbano cita a necessidade de pensar as cidades médias (AMORIM FILHO; SERRA, 2001). Argumentava-se que a insuficiência de centros intermediários dinâmicos estava entre as causas que dificultavam uma interiorização efetiva do país (SPOSITO, 2001; CASTELLO BRANCO, 2006).

Porém, uma vez que inexiste correspondência exata entre o tamanho de uma cidade e seu papel na rede urbana (CHRISTALLER, 1966), a população torna-se insuficiente para traduzir a diversidade de funções desses locais como um todo e, em especial, das cidades médias (SPOSITO, 2001; CASTELLO BRANCO, 2006; OLIVEIRA; MAGALHÃES, 2010). Nesse sentido, este trabalho junta-se a outros, como os de Andrade e Lodder (1979), Pereira (1977), Pereira e Lemos (2003) e Castello Branco (2007), no esforço de refinar empiricamente a identificação das cidades médias no caso brasileiro.

\subsection{A Teoria do Lugar Central como instrumento de investigação da rede de cidades}

Discutir hierarquias de cidades sob uma perspectiva de papel funcional e a consequente rede urbana que disso emerge passa necessariamente pelos trabalhos de Christaller (1966, [1933]) e Lösch (1954 [1944]), autores precursores da Teorias do Lugar Central (TLC). Por meio dela, procura-se explicar por que centros hierarquicamente diferenciados - medida dada pela complexidade dos bens ofertados em cada um dos lugares - se encontram em determinadas localizações e frequência em uma economia.

Enquanto Christaller desenvolve sua teoria supondo que as firmas tomam suas decisões baseadas na ótica da demanda por bens, Lösch assume que a escolha estratégica será dada pela análise da capacidade de oferta. Comum a ambos é a conclusão de que, num espaço homogêneo, se formariam centros urbanos de diversas dimensões - com áreas de atuação hexagonais -, cujas posições relativas e o arranjo geográfico podem ser previstos a partir das economias de escala, dos custos de transporte e da dimensão da demanda dos diversos bens.

De modo geral, pode-se dizer que o que diferencia os dois autores é a forma de abordarem a composição dos lugares centrais, pois, enquanto Christaller apresenta um sistema que pode ser visto como top-down, com contornos indutivistas, mais baseado em observações e intuição, Lösch desenvolve um modelo bottom-up, seguindo linhas dedutivistas que partem de ideias propriamente econômicas, mais especificamente microeconômicas, em que agentes e firmas agem de forma maximizadora (PARR, 2002).

No Brasil, o estudo da rede urbana com base na TLC tem longa tradição em publicações conduzidas pelo Instituto Brasileiro de Geografia e Estatística (IBGE), que, 
em 1972, com a Divisão do Brasil em Regiões Funcionais Urbanas, publicou o primeiro estudo do gênero; a mais recente, Região de Influência das Cidades (Regic), é de 2007. Nessa abordagem, parte-se da ideia de que a organização espacial do território é manifestada tanto por elementos fixos - cidades, indústrias, etc. - como pelos fluxos que estabelecem interações entre eles. Dessa interação surgem as redes, onde os centros se articulam pelas funções que oferecem, gerando com isso as configurações de hierarquias sobre o território.

Assim, reconhecendo a relevância da TLC e do IBGE como instituição com credenciais, neste trabalho propõe-se a utilização de uma metodologia para classificação da rede que consiga capturar suas singularidades de uma maneira próxima àquela do Regic, mas em um formato que facilite a replicabilidade e a possibilidade de comparações intertemporais o que, pelo Regic, fica comprometido em função das mudanças metodológicas entre os estudos.

\subsection{A estrutura setorial de empregos como identificador das hierarquias urbanas}

Assume-se aqui que a distribuição setorial dos empregos nas cidades entre atividades-chave é capaz de apresentar um retrato da sua inserção na rede, seja mediante uma oferta maior de serviços específicos, em uma abordagem próxima à de Christaller (1966) e Lösch (1954), seja por meio de sua capacidade de criação de economias de aglomeração, advindas da especialização/diversificação das cidades nas ideias de Marshall (1890) e Jacobs (1969).

Entende-se ainda que a base terciária é fundamental nesse processo, e a capacidade de polarização de um local, manifestada no seu nível hierárquico dentro da rede, se caracterizará, sobretudo, pela dinâmica do seu setor terciário (SIMÕES et al., 2006). Nesse sentido, o nível de complexidade e encadeamento da base produtiva de uma cidade reflete-se no tipo de serviços oferecidos nesses locais.

Como resultado, a área de influência formada por uma localidade e sua consequente articulação no plano regional estará diretamente relacionada a dois fatores: (i) à habilidade de internalização na sua base produtiva das atividades caracterizadas por uma baixa capacidade de transportabilidade; (ii) ao fluxo de trocas que o centro estabelece com seu entorno, caracterizado pelo deslocamento de pessoas em busca dos serviços e mercadorias ofertados (LEMOS, 1991).

Porém, a reunião sobre a nomenclatura "serviços" não consegue expressar a variabilidade das atividades desenvolvidas nesse setor e, em especial, daquelas que conferem maior poder de centralidade e geração de economias de urbanização às cidades. Por isso, segue-se aqui a proposta de Browning e Singelman (1978) - adaptada para o Brasil por Simões et al. (2006) -, que particiona o setor de acordo com a orientação da demanda desses produtos. 
No grupo de serviços públicos incluem-se aqueles demandados coletivamente, como ensino, saúde e segurança; já os serviços pessoais concentram as atividades demandadas individualmente, como lazer; os serviços produtivos relacionam-se aos que são demandados pelas empresas durante seu processo produtivo, como as intermediações financeiras e de assessoria empresarial; por fim, os serviços distributivos são demandados pelas empresas após a produção, como armazenamento e transporte, por exemplo.

Acredita-se que, ao utilizar o setor terciário de maneira particionada, é reforçada e mais bem compreendida a capacidade de polarização dele perante a indústria, a agropecuária e a construção civil² - os demais setores que aqui são utilizados -, sem com isso retirar o protagonismo destes, uma vez que são vitais para aquelas economias.

\section{Metodologia}

As técnicas de grupamentos, ao simplificar as informações com base na geração de classificações dos objetos sob análise em grupos os mais homogêneos possíveis, permitem a criação de tipologias/taxonomias que proporcionam um entendimento mais direto das características inerentes aos objetos analisados (KAUFMAN; ROUSSEEUW, 2009). No entanto, para que a técnica realmente seja eficaz nesse processo, é necessária uma base de dados que retrate de maneira satisfatória os objetos em análise. A fim de evidenciar esses procedimentos, aqui são discutidos o método e a base de dados utilizada no trabalho.

\subsection{Método}

Definida como um algoritmo para identificação de grupamentos não hierárquicos, a técnica Partition Around Medoids (PAM) destaca-se por utilizar como ponto focal os medoides, o objeto do cluster que tem a menor dissimilaridade média para os demais. ${ }^{3}$ Outros métodos do gênero - como k-means -, em relação à PAM, são mais sensíveis à presença de outliers (KAUFMAN; ROUSSEEUW, 2009).

$O$ algoritmo utilizado na PAM se baseia na alocação de $n$ objetos em $k$ grupamentos previamente estabelecidos. A partir disso, são definidos os $k_{i}$ medoides, ou seja, os objetos focais de cada grupamento. Feito isso, os demais objetos são alocados nos grupos a partir da minimização da dissimilaridade interna por meio de

2 Foi desconsiderado o setor extrativista por acreditar-se que o nível de dinâmica municipal/ regional gerado por ele na economia é muito baixo, de forma que não confere poder de centralidade a um lugar.

3 Ainda de outra forma, o medoide é o objeto mais ao centro do grupo e, por isso, seu objeto mais representativo. 
uma função objetivo - resolvida mediante o emprego de processos numéricos interativos -, de forma que a alocação final produza diferença mínima entre a soma dos pontos e aquele indicado como medoide do cluster.

Para sua aplicação, é necessário que seja definida uma métrica de dissimilaridade $d(i, j)$ entre os pontos. Neste trabalho, optou-se pela métrica do quadrado das distâncias euclidianas para o cálculo das dissimilaridades, em razão de essa medida dar maior peso às diferenças intermunicipais - para o caso aqui considerado nos indicadores utilizados.

Assim, o processo de resolução implica a minimização da função F(x) em (1) sujeita à função de restrição ligada à dissimilaridade em (2), conforme:

(1) $F(x)=\min \sum_{i=1}^{n} \sum_{w=1}^{n} d\left(i, m_{w}\right)$

(2) $d\left(i, m_{1}\right) \leq d\left(i, m_{w}\right) \forall w=1, \ldots, k$.

No contexto deste trabalho, parte-se da ideia de que as escalas são importantes. Em outras palavras, ter mais trabalhadores em determinado setor influencia na definição de seu alcance e, consequentemente, de sua área polarizada. Da mesma forma, os setores para os quais uma cidade se volta, refletidos no montante de trabalhadores nele alocados, não são frutos do acaso; pelo contrário, são escolhas - ou consequências - que retratam suas vantagens locacionais e a posição regional em que estão inseridas.

Na linguagem do método, esses dois argumentos têm consequências fundamentais nos resultados e são traduzidos pela utilização dos dados brutos de empregos - em vez de participações setoriais - e pela não padronização das variáveis, o que implica que as colunas - os setores - têm pesos distintos, conforme suas diferentes escalas e variâncias.

Nota-se ainda que, para a implementação da análise, é necessário preestabelecer o número de grupamentos subjacentes aos objetos. Assim, assume-se aqui a existência de 11 níveis da rede nos quais as cidades brasileiras estão alocadas. Tal escolha foi feita utilizando como referência o Regic 2007, que define essa quantidade de níveis para a rede urbana, bem como por intermédio da análise gráfica de average silhouette width - cujos resultados podem ser consultados no Apêndice A. Para o ano de 2010, a análise gráfica indicou 11 grupamentos como número ótimo. Já para o ano de 2000, o resultado gráfico indicou que 8 grupamentos permitiriam uma definição adequada. Todavia, uma vez que há pouca diferença na average silhouette width entre 8 e 11 grupamentos, manteve-se este último número, para que os resultados conservassem capacidade de comparabilidade entre os 
dois períodos aqui analisados e com o Regic, fato que pode ser explorado em outros estudos.

Adicionalmente à análise PAM, para tentar capturar de maneira mais clara a natureza da correlação entre os setores de atividades econômicas utilizadas, realiza-se uma Análise de Componentes Principais (ACP) a partir da mesma base. Nessa técnica, por meio de combinações lineares não correlacionadas (ortogonais) das variáveis, procura-se capturar a maior parte possível da variância dos dados, com os componentes principais ordenados de acordo com a parcela da informação total que cada um retém. Assim, utiliza-se a ACP com o propósito de realizar uma interpretação mais efetiva da PAM, evidenciando a distribuição das hierarquias em termos de direção e peso das variáveis de que se faz uso na composição da rede.

Mais especificamente, emprega-se a representação gráfica biplot, possuidora de algumas propriedades bastante úteis no que se refere ao emprego da ACP neste trabalho. Dentre eles, destacam-se: (i) o cosseno do ângulo entre quaisquer dois vetores representando variáveis é o coeficiente de correlação entre essas variáveis; (ii) o cosseno do ângulo entre qualquer vetor representando uma variável e o eixo representando um componente principal é o coeficiente de correlação entre essas duas variáveis; (iii) a distância euclidiana entre quaisquer dois objetos é proporcional à distância de Mahalanobis entre eles (JOLLIFFE; CADIMA, 2016).

\subsection{Base de dados}

Com relação à base de dados, duas seriam as possibilidades que possuem uma cobertura capaz de ser desagregada no nível de municípios: Censo Demográfico e Relação Anual de Informações Sociais (Rais). Porém, para os objetivos deste trabalho, a Rais apresenta duas limitações importantes perante o Censo: i) as informações dizem respeito ao local de declaração feito pela firma, enquanto, no Censo, ao entrevistar os indivíduos nos domicílios, é coletada uma informação de local de trabalho da pessoa; ii) a Rais, contrariamente ao Censo, está limitada ao mercado de trabalho formal, restringindo sua abrangência e gerando subamostragens não desprezíveis, especialmente em setores como o agropecuário e em alguns ramos de serviços.

Fundamentando-se na definição do Censo como base de dados primária, em função da criação de novos municípios entre 2000 e 2010, para compatibilização das malhas, os municípios criados a partir de 2000 foram reagrupados à sua sede anterior, ou, no caso de municípios com origens múltiplas, àquele que lhe cedeu maior área quando de sua criação. As malhas compatibilizadas foram agregadas, por sua vez, nas Áreas de Concentração da População (ACPs), constituídas de grandes aglomerações formadas por mais de um município com base nas relações de fluxos para trabalho e estudo entre si. As ACPs apresentam-se no total de quarenta 
e contém 336 municípios. Assim, para a análise, obtém-se 5.217 unidades de municípios e/ou ACPs.

Para a identificação dos trabalhadores e dos respectivos setores de atuação, no Censo 2000 foi utilizada a variável V4462 e, no Censo 2010, a variável V6472. Ambas se referem ao código da Classificação Nacional de Atividades Econômicas Domiciliar, utilizada em pesquisas domiciliares do país e derivada da Classificação $\mathrm{Na}$ cional de Atividades Econômicas (CNAE). Posteriormente, os trabalhadores foram agrupados em setores de atividades econômicas da seguinte forma: agropecuária, indústria, construção civil, serviços públicos, serviços pessoais, serviços distributivos e serviços produtivos.

\section{Resultados}

A aplicação desenvolvida neste trabalho, apoiando-se em uma abordagem que privilegia aspectos funcionais das cidades, procura identificar as relações hierárquicas que emergem entre os centros urbanos e explorar os grupos que contêm as cidades médias brasileiras em 2000 e 2010. Assim, primeiramente são explorados aspectos gerais da rede de cidades para, então, aprofundar-se nas características das hierarquias das cidades médias.

\subsection{Identificação e caracterização da rede de cidades para os anos 2000 e 2010}

Na base censitária para a qual foi aplicada a análise PAM, presente na Tabela 1, chama atenção o peso exercido pelo Setor Agropecuário e o de Serviços Pessoais, os quais apresentam, respectivamente, as maiores mediana e média em número de trabalhadores. Do mesmo modo, o crescimento das atividades de Serviços Produtivos entre os dois anos expõe um aspecto de mudança importante na economia brasileira, pois esse tipo de serviço, por ser menos ubíquos, está geralmente associado a estágios de desenvolvimento mais avançados.

Na Tabela 2, são apresentados os resultados da PAM,4 e a cada grupamento é atribuída uma nomenclatura. Além disso, estão presentes dois resultados importantes de validação dos resultados, o ajuste interno médio do grupo e a cidade/ACP que melhor caracteriza aquele grupamento. No que diz respeito à consistência dos grupamentos, quanto mais próximos dos extremos da hierarquia, maiores as similaridades das localidades pertencentes àqueles grupos. Por esse motivo, investigar as fontes de variabilidade dos grupos intermediários, com base na posição ocupada pelas cidades médias, ressalta a importância dos objetivos buscados neste trabalho.

4 O Apêndice B, presente no final do trabalho, pode ser consultado para mais informações com relação aos resultados. Ainda, no link http://bit.ly/Cidades_Medias podem ser acessados os resultados detalhados da composição dos grupos. 


\begin{tabular}{|c|c|c|c|c|c|c|c|}
\hline & agropecuária & indústria & construção & $\begin{array}{l}\text { serviços } \\
\text { públicos }\end{array}$ & $\begin{array}{l}\text { serviços } \\
\text { pessoais }\end{array}$ & $\begin{array}{c}\text { serviços } \\
\text { distributivos }\end{array}$ & $\begin{array}{c}\text { serviços } \\
\text { produtivos }\end{array}$ \\
\hline & \multicolumn{7}{|c|}{2000} \\
\hline mínimo & 28 & o & 0 & 6 & 9 & 0 & o \\
\hline máximo & 53,554 & 1.442 .598 & 498,919 & 1.027 .944 & 2.636 .923 & 535,04 & 1.011 .057 \\
\hline média & 2,322 & 1,678 & 875 & 1,924 & 4,048 & 639 & 885 \\
\hline $1^{\circ}$ quartil & 856 & 89 & 77 & 240 & 301 & 40 & 21 \\
\hline $2^{\circ}$ quartil & 1,608 & 226 & 167 & 439 & 666 & 89 & 56 \\
\hline \multirow[t]{2}{*}{$3^{\circ}$ quartil } & 2,903 & 645 & 380 & 868 & 1,585 & 215 & 159 \\
\hline & \multicolumn{7}{|c|}{2010} \\
\hline mínimo & 50 & o & 3 & 74 & 11 & 0 & o \\
\hline máximo & 80,493 & 1.415 .532 & 590,901 & 1.284 .087 & 3.105 .514 & 635,367 & 1.593 .064 \\
\hline média & 2,36 & 2,031 & 1,206 & 2,55 & 5,125 & 787 & 1,384 \\
\hline $1^{\circ}$ quartil & 815 & 102 & 111 & 320 & 385 & 43 & 36 \\
\hline $2^{\circ}$ quartil & 1,559 & 281 & 240 & 591 & 871 & 102 & 90 \\
\hline $3^{\circ}$ quartil & 2,905 & 845 & 564 & 1,16 & 2,108 & 259 & 252 \\
\hline
\end{tabular}

Tabela 1 - Características da base (em número de trabalhadores, 2000 e 2010)

Fonte: Elaboração própria com base nos resultados da PAM.

\begin{tabular}{l|c|c|c|c|c|c}
\multicolumn{1}{c|}{ grupo } & tamanho & ajuste & medoide & tamanho & ajuste & medoide \\
\hline megalópole & 1 & 0 & ACP São Paulo & 1 & 0 & ACP São Paulo \\
\hline grande metrópole & 1 & 0 & ACP Rio de Janeiro & 1 & 0 & ACP Rio de Janeiro \\
\hline metrópoles & 8 & 0,4207 & ACP Porto Alegre & 10 & 0,4096 & ACP Porto Alegre \\
\hline grandes cidades & 9 & 0,3494 & ACP Campo Grande & 20 & 0,3044 & ACP Campo Grande \\
\hline $\begin{array}{l}\text { cidades médias } \\
\text { de longo alcance }\end{array}$ & 27 & 0,2661 & $\begin{array}{c}\text { ACP São José } \\
\text { do Rio Preto }\end{array}$ & 44 & 0,2395 & Uberaba \\
\hline $\begin{array}{l}\text { cidades médias } \\
\text { de médio alcance }\end{array}$ & 108 & 0,3528 & Varginha & 197 & 0,1856 & Paranavaí \\
\hline $\begin{array}{l}\text { cidades médias } \\
\text { de curto alcance }\end{array}$ & 275 & 0,1360 & $\begin{array}{c}\text { São José } \\
\text { do Rio Pardo }\end{array}$ & 302 & 0,1346 & Colinas \\
\hline pequenas cidades I & 575 & 0,1910 & Coreaú & 583 & 0,1712 & Pompéu \\
\hline pequenas cidades II & 600 & 0,2316 & Arapoti & 834 & 0,2733 & Ribeirão Branco \\
\hline núcleos urbanos I & 1,508 & 0,2880 & Curimatá & 1,395 & 0,2518 & Vera Cruz \\
\hline núcleos urbanos II & 2,106 & 0,5754 & São Julião & 1,831 & 0,5524 & São Miguel do Sabugi
\end{tabular}

Tabela 2 - Caracterização dos grupamentos formados (2000 e 2010)

Fonte: Elaboração própria com base nos resultados da PAM. 
Quanto aos medoides, percebe-se que o topo da hierarquia brasileira é ocupado pela ACP de São Paulo, caracterizada como megalópole nacional. Sua inserção, inclusive nas grandes cadeias mundiais, efetiva São Paulo numa posição de comando maior da rede. Na sequência, também como elemento único, aparece como grande metrópole a ACP do Rio de Janeiro. Seu histórico a coloca em posição única, pois, ainda que não possua a força econômica de São Paulo, distingue-se das demais capitais por sua relevância política e produtiva.

No grupo das metrópoles estão cidades já bastante sólidas, todas capitais de estados e, também por isso, com forte participação na articulação nacional. Por sua vez, as grandes cidades são compostas de capitais e cidades que, embora já bem estabelecidas e articuladas, têm sua emergência relacionada ao processo de interiorização do país.

No que tange às cidades médias, a primeira categoria é chamada, aqui, de cidades médias de longo alcance, grupo caracterizado por centros com economias dinâmicas e que possuem inserção bastante sólida no contexto regional. As cidades médias de médio alcance abrigam os centros que, apesar de ainda não terem sido capazes de se inserir no cenário regional de maneira ampla, têm uma inserção que não se limita ao atendimento de uma demanda local, constituindo-se, assim, em atores de intermediação regional. Por fim, têm-se as cidades médias de curto alcance, as quais se apresentam como cidades que, apesar de em nível macrorregional terem uma condição de inserção local, exercem influência sobre a vizinhança imediata.

Por fim, a base hierárquica é composta de quatro grupos cuja estrutura, no geral, não lhes confere poder de escala, seja por se situarem muito próximas a centros já sólidos, seja por possuírem características internas que fazem desses lugares centros muito pequenos.

As Figuras 1 e 2 foram construídas a fim de fornecer uma dimensão visual sobre como se dá a composição entre os setores de atividades em cada uma das hierarquias urbanas. Os resultados permitem observar o papel central desempenhado pela agropecuária e pelos serviços produtivos na delimitação das hierarquias urbanas na rede brasileira, pois, entre esses dois setores, para ambos os anos, à medida que se desce nos níveis hierárquicos, aumenta a participação do setor agropecuário e diminuem os serviços produtivos.

Esse tipo de serviço, sobretudo em virtude de sua característica de auxiliar no processo produtivo, tem sua demanda determinada, em grande medida, pelas decisões de investimento das empresas e, por isso, afeta diretamente a capacidade de centralidade das cidades. Também são resultado da maior diversificação das economias locais, o que, por meio do aumento da densidade econômica, justifica não só a expansão de atividades derivadas, como, principalmente, a própria oferta de serviços modernos presentes no grupo. 


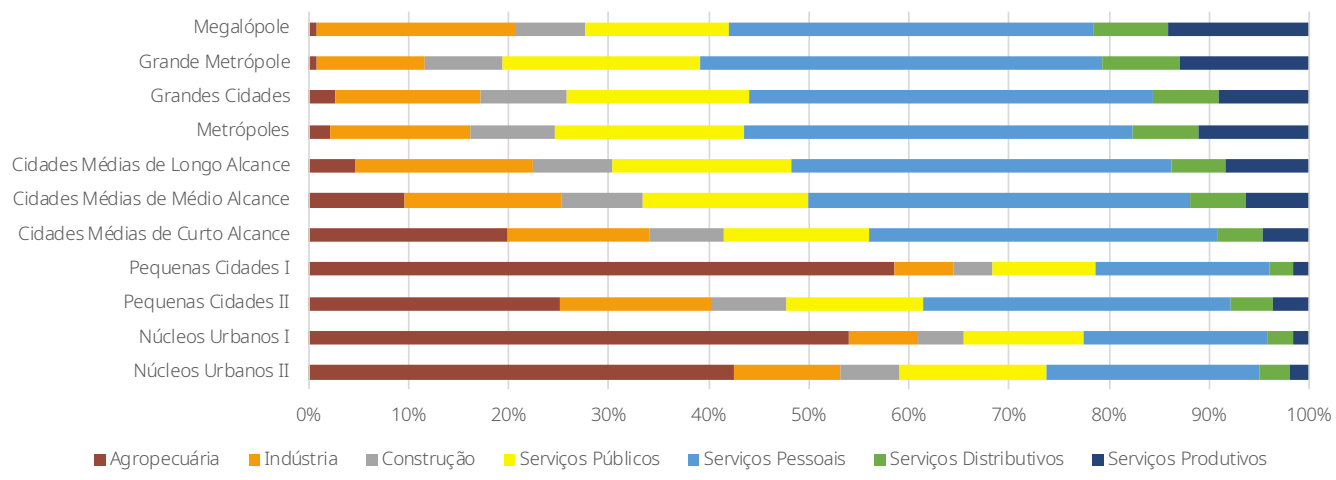

Figura 1 - Hierarquias urbanas por setores de atividades econômicas (2000) Fonte: Elaboração própria com base nos resultados da ACP.

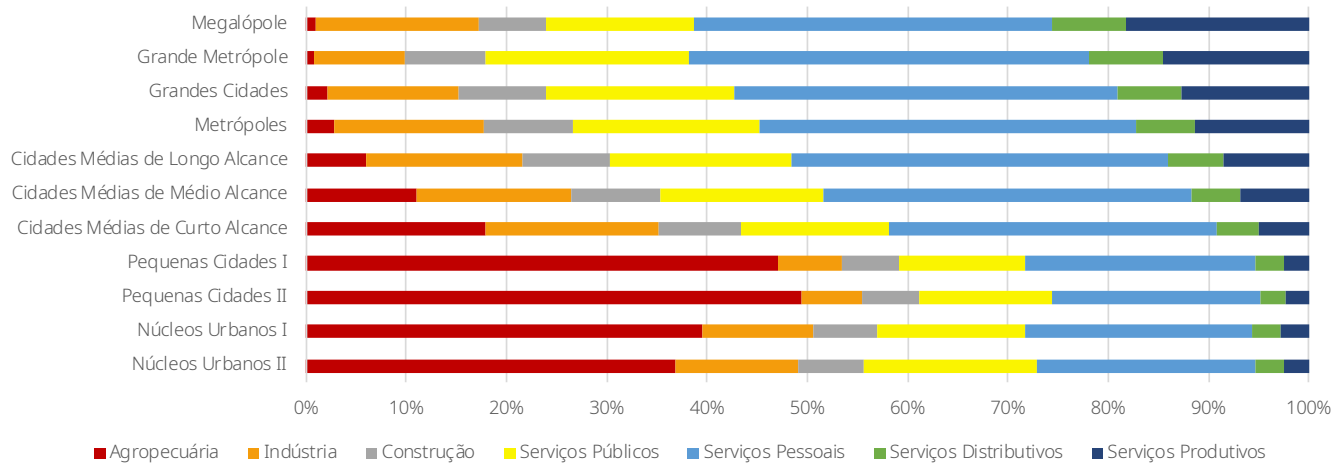

Figura 2 - Hierarquias urbanas por setores de atividades econômicas (2010) Fonte: Elaboração própria com base nos resultados da ACP.

Nota-se ainda, pela comparação entre os dois anos, que a média de participação dos setores se manteve bastante estável para cada um dos grupos, numa indicação de que cada hierarquia cumpre um papel relativamente bem definido. Desse modo, as mudanças entre os dois anos devem-se mais às alterações de composição nas estruturas internas das cidades, que levam a um realocamento do seu nível hierárquico.

Nas Figuras 3 e 4, são apresentados os biplots da Análise de Componentes Principais (ACP) resultantes da utilização das participações setoriais de empregos. Nas figuras, os municípios são categorizados de acordo com o pertencimento nas hierarquias estabelecidas pela PAM. Esse fato não tem nenhum efeito sobre a geração dos resultados, mas, para os propósitos para o qual foi aplicada a ACP, auxiliam na compreensão de como as cidades se distribuem em função das suas estruturas produtivas. Nota-se, igualmente, que o tamanho dos vetores nos gráficos se dá em função da carga daquela variável na definição do componente. 


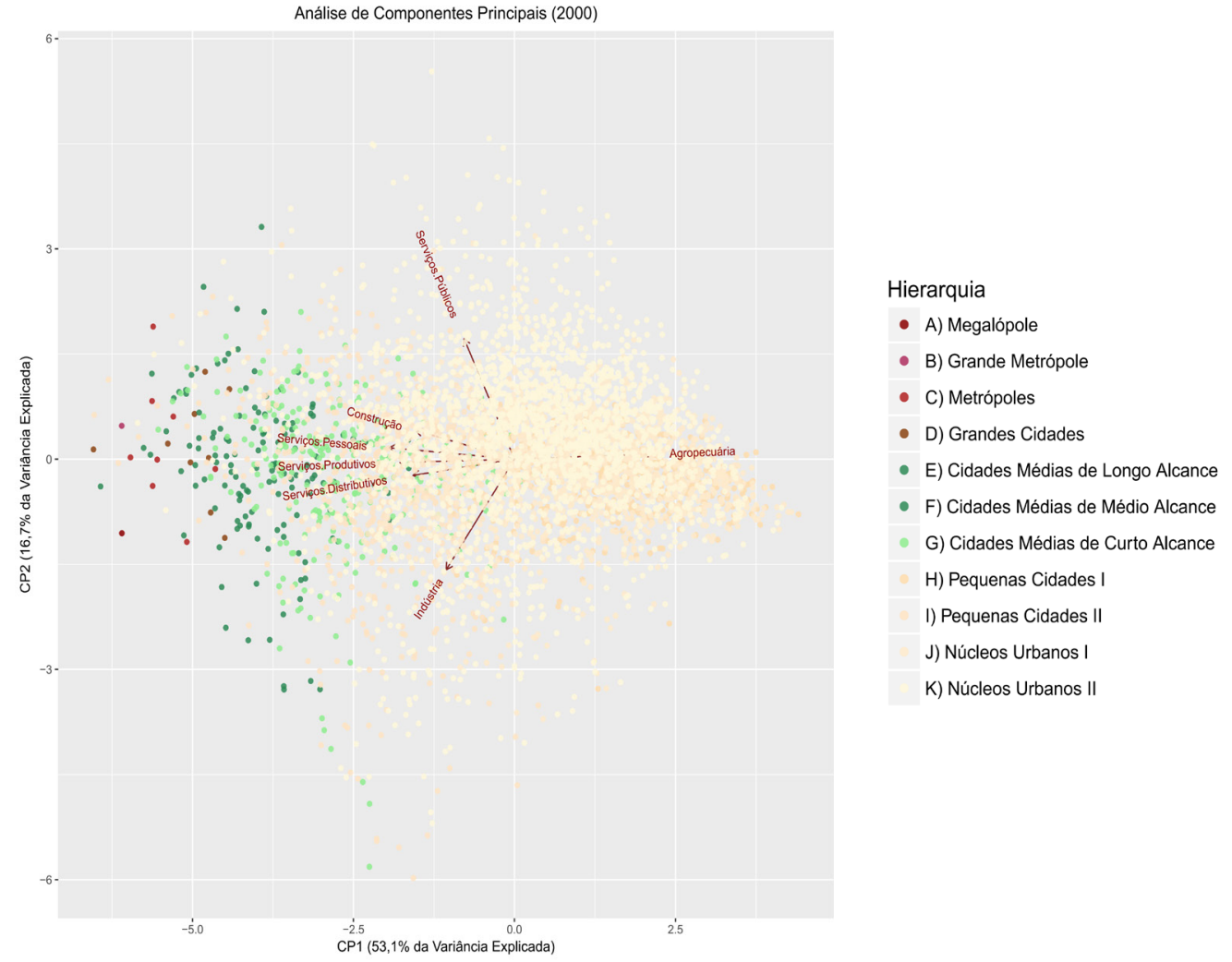

Figura 3 - Análise de componentes principais para as hierarquias (2000)

Fonte: Elaboração própria com base nos resultados da ACP.

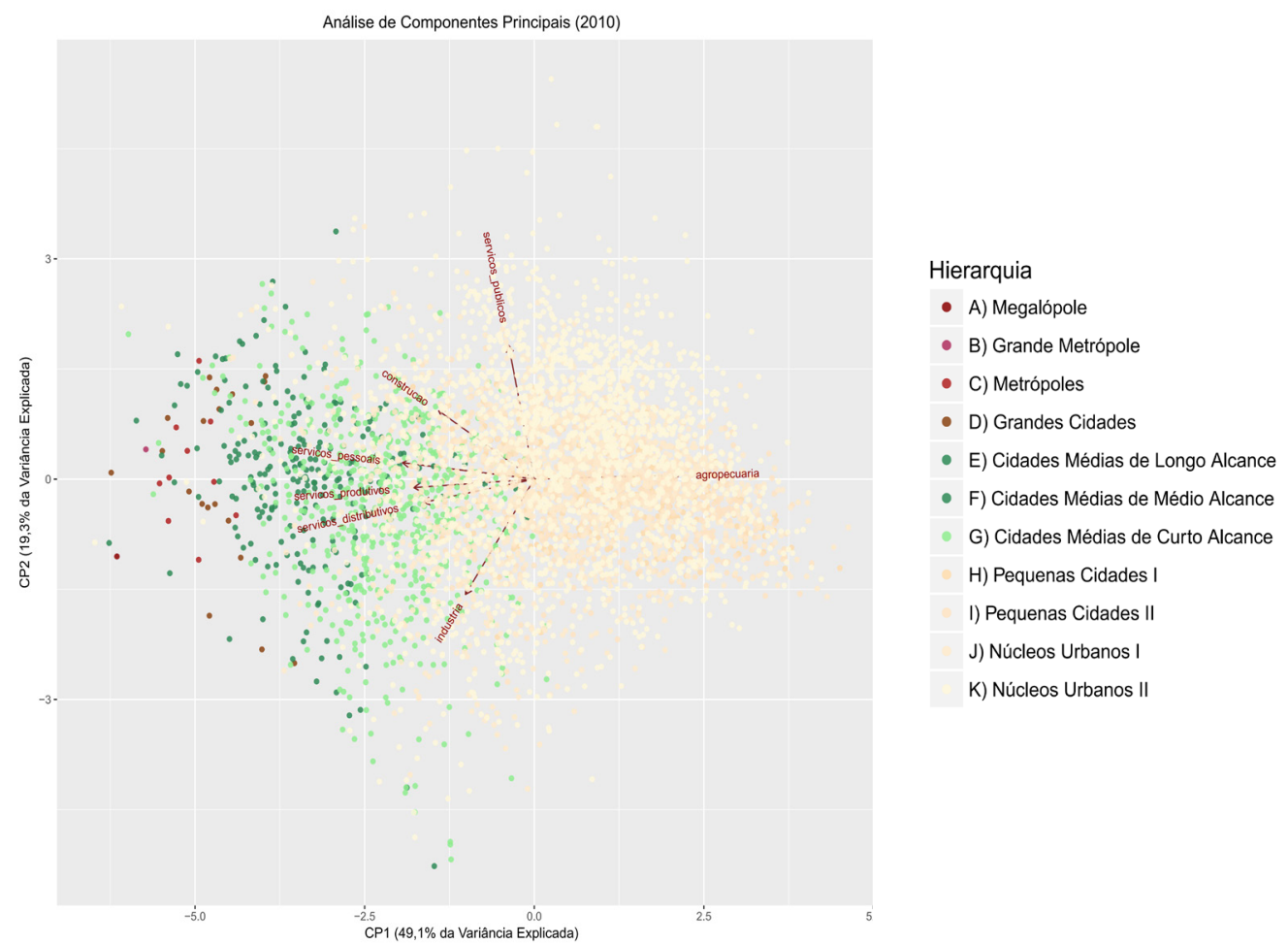

Figura 4 - Análise de componentes principais para as hierarquias (2010) Fonte: Elaboração própria com base nos resultados da ACP. 
Tanto para 2000 como para 2010, os dois primeiros componentes captam cerca de 70\% da variância dos dados. Da mesma forma, nos dois anos, o comportamento em termos de cargas fatoriais foi muito próximo para os vetores referentes aos setores econômicos - variando na segunda casa decimal. As mudanças mais importantes foram aquelas relativas à distribuição da nuvem de pontos, ou seja, de realocação dos municípios. Essa constatação reforça a ideia de que as atividades aqui utilizadas identificam de maneira relativamente bem definida as funções desempenhadas na rede pelos diferentes níveis hierárquicos.

Das figuras, percebe-se um padrão em que, quanto maior for a hierarquias das cidades, mais à esquerda da figura elas se situam. Além disso, nessa região, encontram-se cidades concentradas próximas aos vetores referentes aos setores da Construção, dos Serviços Distributivos, Produtivos e Pessoais. Associada aos grupamentos hierárquicos inferiores, verifica-se uma dominância dos Serviços Públicos, da Agropecuária e, em alguma medida, da Indústria.

No primeiro componente, a Agropecuária foi o único setor com carga fatorial positiva, na ordem de 0,50. Uma vez que nos gráficos ela se associa às cidades de menor hierarquia, esses resultados indicam que, no geral, municípios mais dependentes desse setor apresentam menor presença de Serviços Produtivos, Distributivos e Pessoais, mas não necessariamente da Indústria e dos Serviços Públicos. No segundo componente, dois foram os setores dominantes: os Serviços Públicos, com carga positiva de 0,71, e a Indústria, com -0,66.

Os resultados sugerem que, recentemente, o setor indústrial não necessariamente está vinculado aos serviços, em especial aqueles ligados às atividades produtivas. Isso indica que nem toda atividade industrial tem capacidade de encadeamento elevado com os demais setores, de modo que não necessariamente possa ser identificada como sinônimo de cidades mais diversificadas e com estruturas econômicas complexificadas.

Além disso, em ambos os casos, a especialização em Serviços Públicos e Indústria independe da categoria das cidades, indicando funções que cidades de qualquer grupamento hierárquico podem assumir. Por sua vez, a Agropecuária é responsável pela maior diferenciação entre as cidades pequenas (quatro categorias inferiores da hierarquia) e as demais frações da rede.

\subsection{Caracterização das cidades médias para os anos 2000 e 2010}

Pela Tabela 3, percebe-se que a alteração da distribuição macrorregional das cidades médias entre 2000 e 2010 foi significativa. Na região Centro-Oeste, manteve-se um padrão bastante similar nos dois anos. Já nas regiões Norte e Nordeste, houve alteração expressiva no número de cidades médias. Destaca-se, ainda, a re- 


\begin{tabular}{l|c|c|c|c|c|c} 
& \multicolumn{2}{c|}{$\begin{array}{c}\text { cidades médias } \\
\text { de longo alcance }\end{array}$} & \multicolumn{2}{c|}{$\begin{array}{c}\text { cidades médias } \\
\text { de médio alcance }\end{array}$} & \multicolumn{2}{c}{$\begin{array}{c}\text { cidades médias } \\
\text { de curto alcance }\end{array}$} \\
\cline { 2 - 7 } & 2000 & 2010 & 2000 & 2010 & 2000 & 2010 \\
\cline { 2 - 7 } sul & 7 & 10 & 26 & 39 & 53 & 20 \\
\hline sudeste & 11 & 17 & 48 & 95 & 105 & 41 \\
\hline centro-oeste & 2 & 2 & 6 & 13 & 25 & 4 \\
\hline norte & 0 & 5 & 10 & 17 & 23 & 58 \\
\hline nordeste & 7 & 10 & 18 & 33 & 69 & 179 \\
\hline TOTAL & 27 & 44 & 108 & 197 & 275 & 302
\end{tabular}

Tabela 3 - Distribuição das cidades médias por grandes regiões (2000 e 2010) Fonte: Elaboração própria com base nos resultados da PAM.

dução do número de cidades médias de curto alcance no Sul e no Sudeste, em 2010. Em termos de números de municípios nesses grupos, houve aumento pouco superior a 3 p.p. no total.

A Figura 5 apresenta as cidades médias classificadas em função tanto das suas hierarquias de pertencimento como das distâncias destas em relação às respectivas capitais em 2000 e 2010. Isso é feito em face do papel central exercido na rede brasileira pelas capitais estaduais, as quais, pela análise desenvolvida, representam em todas as unidades federativas a hierarquia mais alta da rede. Assim, é razoável supor que são as capitais o mais alto centro de comando com o qual as cidades médias se relacionam mais intimamente, de modo que se torna importante que estas sejam situadas em relação às esferas de hierarquias mais altas com as quais concorrem por espaço econômico.

Os gráficos possibilitam a observação de padrões regionais que refletem processos históricos relacionados à formação/evolução econômica e demográfica do país, com reflexos diretos na configuração da rede brasileira. Dois merecem destaque: (i) uma presença menor de cidades na categoria de cidades médias - e, ainda que não retratado no gráfico, de hierarquias superiores de forma mais geral -, quando cruzada em direção a oeste uma "linha” que vai de Belém (PA), passa por Palmas (TO) e Goiânia (GO) e chega a Campo Grande (MS); (ii) em certa medida, fator que, ao longo do tempo, ajuda a romper com a observação anterior, isto é, a expansão de cidades que acompanharam a migração via fronteira agrícola no Centro-Oeste e no Norte do país.

Em 2010, houve notável alteração do padrão espacial das cidades médias na rede urbana brasileira, com destacado processo de interiorização desses centros, particularmente no Norte e Nordeste do país. Se em 2000 cidades médias podiam 

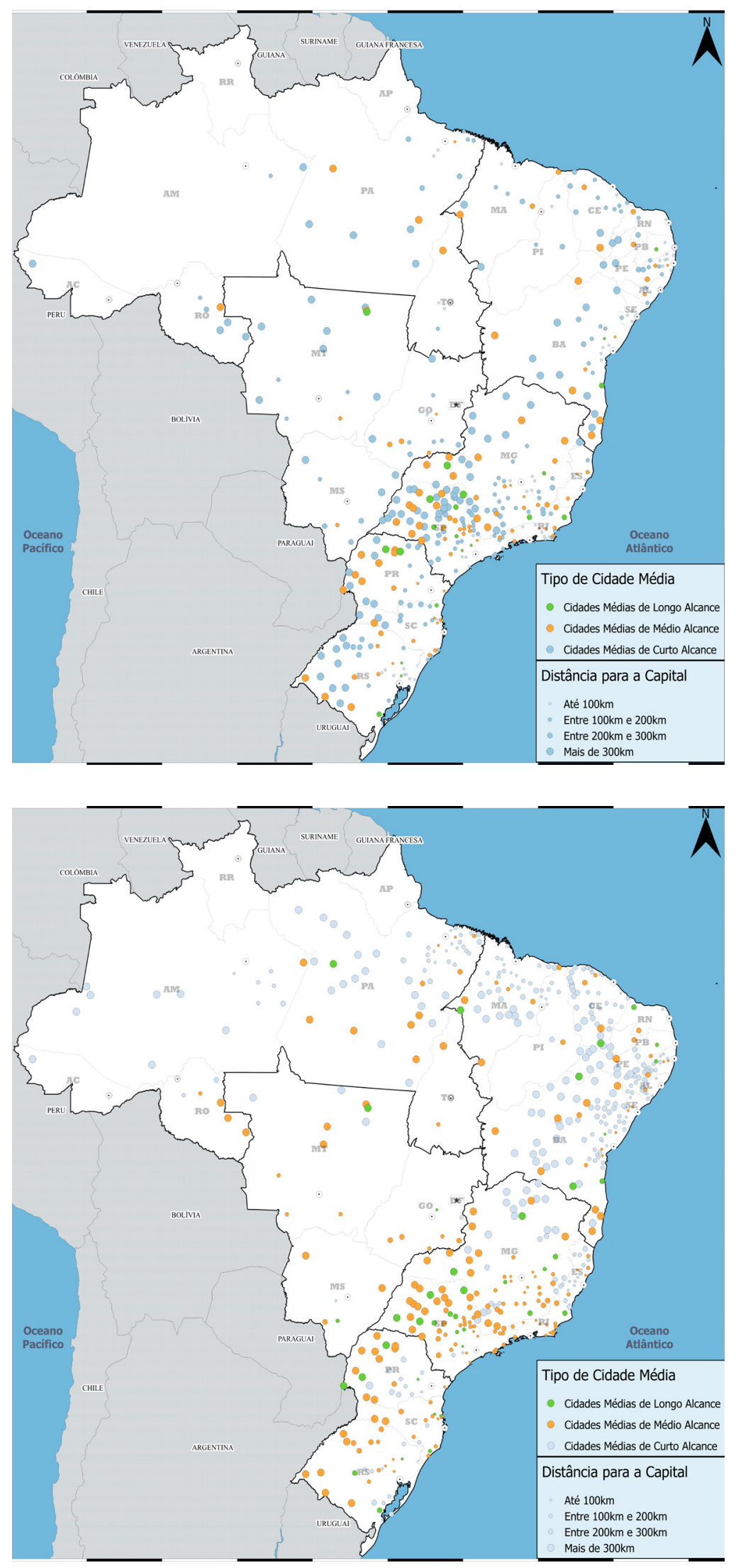

Figura 5 -

Distribuição e

distância para as

capitais das cidades

médias (2000 e 2010)

Fonte: Elaboração

própria com base nos

resultados da PAM. 
ser associadas a diferentes capitais, em 2010 o Norte - cujas capitais, com exceção de Belém (PA) e Manaus (AM), cumprem função de cidades médias - era a única região em que esse tipo de cidade seguia ocupando tal posição, estando em posições superiores nos demais casos.

Em termos de distribuição espacial, a avaliação dos medoides, em conjunção com a percepção visual dos gráficos, indica que as cidades médias de longo alcance tendem a estar mais distantes da influência dos grandes nós da rede, de forma que possam estabelecer uma área de polarização própria e, com isso, exercer um protagonismo regional ativo.

É esse o caso, por exemplo, de São José do Rio Preto, em São Paulo, localizada a $350 \mathrm{~km}$ de Campinas - cidade com maior hierarquia que é mais próxima. A despeito de estar perto de cidades com mesma hierarquia - como Ribeirão Preto (SP) e Uberlândia (MG) -, por se situar mais a oeste do estado de São Paulo, sofre menos com a zona de influência das cidades com maior força polarizadora da rede - São Paulo e Rio de Janeiro.

Por sua vez, as cidades médias de médio alcance, apesar de estarem mais próximas dos grandes centros, têm uma posição geográfica de intermediação do território. Varginha (MG) situa-se em uma posição quase que equidistante entre dois importantes polos. De um lado, sofre a influência de Belo Horizonte (MG), principal centro da sua rede estadual, e, de outro, é pressionada por São Paulo (SP), o principal nó da rede nacional. Assim, assume posição ambígua, visto que, se por um lado estrategicamente está bem situada na rede, sua posição dificulta seu potencial de polarização regional.

Já as cidades médias de curto alcance sofrem mais os efeitos das outras hierarquias lhes conferindo uma posição de spillovers. É o caso de São José do Rio Pardo (SP), que tem seu potencial de polarização reduzido, uma vez que está situada a 150 km de Ribeirão Preto (SP) e, mais importante, está à mesma distância de Campinas (SP), de modo que seu papel regional tende a ser de complementariedade em relação a esses centros. Da mesma forma, Colinas (MA) em 2010, pois, apesar de estar nas imediações de cidades que figuram entre as maiores hierarquias na rede nacional, também está próxima àquelas de maior hierarquia da região - Teresina (PI) e Balsas (MA).

Dessa análise, permite-se levantar algumas hipóteses sobre a evolução recente da rede de cidades e, em especial, das cidades médias no Brasil. Ainda que sua distribuição reflita um processo de longo prazo associado ao movimento de ocupação territorial/econômica do país, houve entre os dois períodos uma redistribuição regional desses centros, com expansão para áreas mais distantes das já conhecidas áreas de concentração econômica/populacional, e essa redistribuição da rede observada no período privilegiou a interiorização. 
Embora mantido similar o tipo de intermediação dos diferentes tipos de hierarquia de cidades médias na rede, quando 2010 é analisado em relação a 2000, dois elementos novos se destacam. Primeiramente, é possível notar um deslocamento dos medoides para o interior do país; em segundo lugar, houve redução do tamanho dessas cidades. Tais fatos associam-se com uma maior integração inter-regional da rede urbana do Brasil, porque, na mesma medida em que essas centralidades avançam em direção ao oeste do país, as quebras entre os diferentes níveis hierárquicos da rede se tornam menos acentuadas, permitindo melhor articulação da rede.

\section{Considerações finais}

Neste trabalho, partiu-se do pressuposto de que as cidades médias são importantes elementos de integração para a rede de cidades do Brasil e, por isso, merecem uma apreciação mais rigorosa na tentativa de identificá-las e caracterizá-las. Nesse sentido, assume-se que, para uma avaliação mais robusta desses centros, deve-se evitar o uso unicamente do tamanho populacional, agregando elementos que consigam captar mais efetivamente a forma de inserção deles na rede.

Assim, propôs-se a utilização de uma metodologia capaz de capturar as singularidades da rede de uma maneira próxima àquela do Regic, mas em um formato que possibilita uma análise intertemporal mais direta. Com esse intuito, assume-se que, aliando a análise de aglomerados PAM com a utilização da distribuição setorial dos empregos nas cidades entre setores de atividades, aqui considerados essenciais, seja possível traçar um retrato importante da inserção das cidades com os respectivos níveis hierárquicos.

Da construção da rede de cidades, percebe-se que, quanto mais no topo da hierarquia o município estiver, maior a influência dos serviços na sua base produtiva. Sobretudo os serviços produtivos de menor ubiquidade na composição produtiva do país como um todo tendem a concentrar-se nos lugares de maior coordenação da rede.

Com relação às cidades médias, os resultados mostram que houve alteração do padrão espacial desses centros na rede urbana, com um notável processo de interiorização em 2010 com relação a 2000. Além disso, se em 2000 cidades médias podiam ser associadas a diferentes capitais, em 2010 apenas na região Norte as capitais continuam a ocupar posição de cidades médias, cumprindo em todos os demais casos uma posição hierárquica superior na rede urbana. Dado que todos os estados do país têm nas suas capitais a cidade de nível hierárquico mais elevado, esse resultado aponta um quadro em que, em 2010, há maior espraiamento das centralidades ao longo da rede do que em 2000. 
Além disso, a distância em relação às capitais também é um fator importante no que diz respeito às cidades médias. Esse padrão espacial pode ser compreendido quando analisado à luz das teorias de aglomerações, pois uma cidade só consegue ganhar espaço hierárquico quando seu potencial de polarização não rivaliza com as esferas superiores da rede, das quais são também dependentes. Por isso, elas precisam encontrar equilíbrio entre uma distância que não as deixe isoladas da rede, mas que ao mesmo tempo não as coloque em competição muito direta com as hierarquias mais altas.

Cabe destacar que o período transcorrido entre os dois pontos analisados 2000 e 2010 - cobre um intervalo bastante intenso para a economia brasileira, com alguns fatos marcantes na história econômica recente do país. Ao afetarem o papel desempenhado por cada cidade na rede, alteram-se também a sua importância e a sua conectividade dentro do sistema, afetando o tipo e a magnitude de seus fluxos com as demais cidades. Como exemplos, destacam-se as políticas de valorização dos salários mínimos, expansão e consolidação de políticas de transferência de renda, além de um cenário internacional favorável para commodities, bens em relação aos quais o Brasil apresenta vantagens comparativas.

Esse fenômeno representa um passo importante na integração regional do Brasil, a qual passa necessariamente por uma interiorização das ocupações no território com a emergência de centros que não só sejam vistos como extensão das capitais, mas que efetivamente consigam desenvolver um dinamismo que lhes dê funcionalidade e, consequentemente, aumentem sua importância na integração da rede. Assim, a reflexão aqui proposta levanta alguns pontos valiosos, pois, além de chamar a atenção para o papel das cidades médias na rede, evidencia uma alteração na sua composição que privilegiou uma interiorização das centralidades intermediárias no país.

\section{Referências Bibliográficas}

AMORIM FILHO, O. B.; SERRA, R. V. Evolução e perspectiva do papel das cidades médias no planejamento urbano e regional. In: Cidades médias brasileiras. Rio de Janeiro: Ipea, pp.1-34, 2001.

ANDRADE, T. A.; LODDER, C. A. Sistema urbano e cidades médias no Brasil. Rio de Janeiro: Ipea, 1979.

ARAÚJO, M. M. S; MOURA, R.; DIAS, P. C. Cidades médias: uma categoria em discussão. In: Dinâmica Urbano Regional Redes e suas Interfaces. Rio de Janeiro: Ipea, pp. 55-72, 2011.

BECKER, B. K.; EGLER III, C. A. G. A economia-mundo e as regiões brasileiras. In: Brasil. Uma nova potência regional na economia-mundo. Rio de Janeiro: Bertrand Brasil, 1994.

BROWNING, H. L.; SINGELMANN, J. The Transformation of the US Labor Force: the Interaction of Industry and Occupation. Politics \& Society, v. 8, n. 3-4, pp. 481-509, 1978. 
CASTELLO BRANCO, M. L. G. Cidades médias no Brasil. In: Cidades médias: produção do espaço urbano e regional. São Paulo: Expressão Popular, pp. 245-277, 2006.

Algumas considerações sobre a identificação de cidades médias. In: Cidades médias: espaços em transição. São Paulo: Expressão Popular, v. 1, pp. 89-112, 2007.

CHRISTALLER, W. Central Places in Southern Germany. Englewoods Cliffs: Prentice Hall, 1966.

CORREA, R. L. Construindo o conceito de cidade média. In: Cidades médias: espaços em transição. São Paulo: Expressão Popular, v. 1, pp. 23-33, 2007.

DINIZ, C. C. Desenvolvimento poligonal no Brasil: nem desconcentração nem contínua polarização. Revista Nova Economia, v. 3, n. 1, 1993.

IPEA, IBGE e UNICAMP. Configuração atual e tendências da rede urbana. v. 1. Série Caracterização e Tendências da Rede Urbana do Brasil. Brasília: Ipea, IBGE, Nesur, 2001.

JACOBS, J. The Economy of Cities. Nova York: Random House, 1969.

JOLLIFFE, I. T; CADIMA, J. Principal Component Analysis: A Review and Recent Developments. In: Philosophical Transactions. Series A, Mathematical, Physical, and Engineering Sciences, v. 374, n. 2065, 2016.

KAUFMAN, L.; ROUSSEEUW, P. J. Finding Groups in Data: an Introduction to Cluster Analysis. Nova Jersey: John Wiley \& Sons, 2009.

LEMOS, M. B. Duas técnicas de análise regional elaboradas a partir de categorias espaciais: a regionalização e o método estrutural-diferencial. Tese de Professor Titular - UFMG 1991.

LEMOS, M. B.; DINIZ, C. C.; GUERRA, L.; MORO, S. A Nova configuração regional brasileira e sua geografia econômica. Estudos Econômicos, v. 33, n. 4, pp. 665-700, 2003.

LÖSCH, A. The Economics of Location. Londres: Yale University, 1967.

MARSHALL, A. Principles of Economics: an Introductory. Londres: Macmillan, 1890.

OLIVEIRA, C.; MAGALHÃES, J. Estrutura produtiva avançada e regionalmente integrada: diagnóstico e políticas de redução das desigualdades regionais. Rio de Janeiro: Ipea, 2010.

PEREIRA, F. M.; LEMOS, M. B. Cidades médias brasileiras: características e dinâmicas urbano-industriais. Pesquisa e Planejamento Econômico, v. 33, n. 1, pp. 127-165, 2003.

PEREIRA, W. K. R. Cidades médias: uma opção no desenvolvimento urbano. Dissertação (Mestrado em Economia) - Universidade de Brasília, Brasília, 1977.

SIMÕES, R.; HERMETO, A. M.; AMARAL, P. V. M. Rede urbana metropolitana: uma análise da estrutura terciária de Belo Horizonte. Ensaios FEE, v. 27, n. 2, pp. 471-513, 2006.

SIMÕES, R.; AMARAL, P. Interiorização e novas centralidades urbanas: uma visão prospectiva para o Brasil. Economia, v. 12, n. 3, pp. 553-579, 2011.

SOBRINHO, E. M. G.; AZZONI, C. R. Aglomerações industriais relevantes do Brasil em 2010. Revista Brasileira de Estudos Regionais e Urbanos, v. 9, n. 1, pp. 1-18, 2016.

SPOSITO, M. E. B. As cidades médias e os contextos econômicos contemporâneos. In: Urbanização e cidades: perspectivas geográficas. São Paulo: Editora da Unesp, pp. 569-607, 2001. 

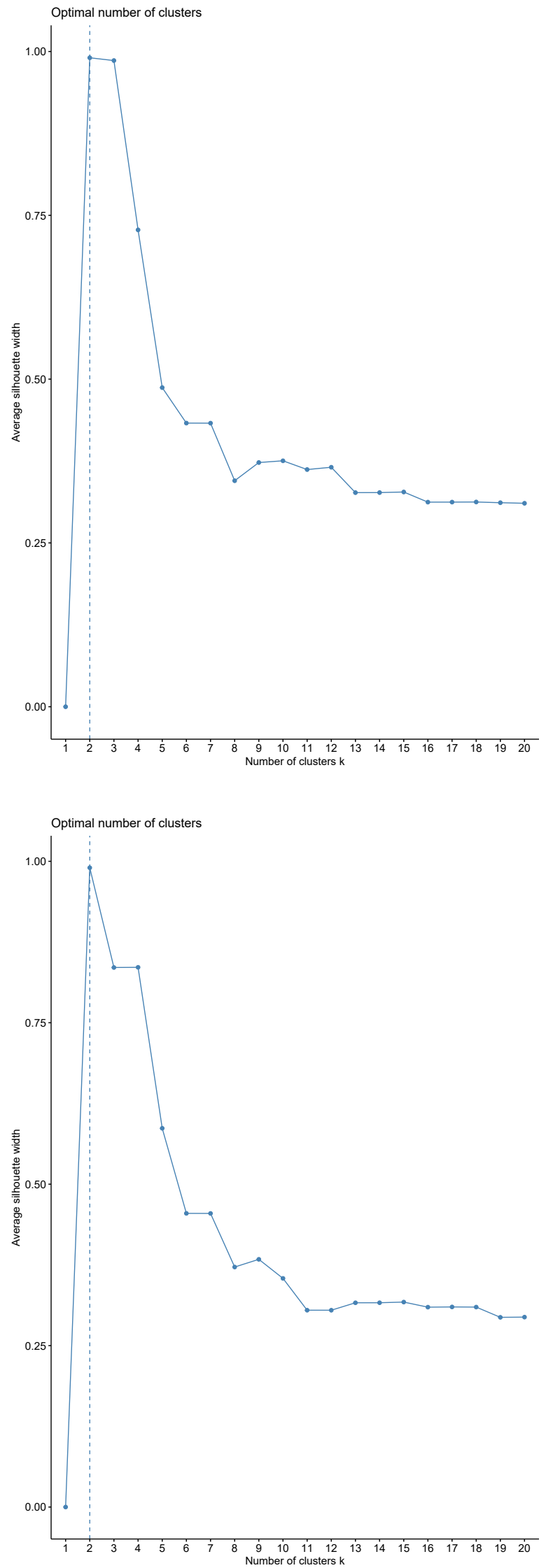

\section{Apêndice A}

Gráficos auxiliares para definição do número de grupamentos: Average silhouette width, ano 2000; Average silhouette width, ano 2010.

Fonte: Elaboração própria com base nos resultados da PAM. 


\begin{tabular}{|c|c|c|c|c|c|c|c|c|c|c|c|c|c|c|}
\hline & \multicolumn{2}{|c|}{ agropecuária } & \multicolumn{2}{|c|}{ indústria } & \multicolumn{2}{|c|}{ construção } & \multicolumn{2}{|c|}{$\begin{array}{l}\text { serviços } \\
\text { públicos }\end{array}$} & \multicolumn{2}{|c|}{$\begin{array}{l}\text { serviços } \\
\text { pessoais }\end{array}$} & \multicolumn{2}{|c|}{$\begin{array}{c}\text { serviços } \\
\text { distributivos }\end{array}$} & \multicolumn{2}{|c|}{$\begin{array}{c}\text { serviços } \\
\text { produtivos }\end{array}$} \\
\hline & 2000 & 2010 & 2000 & 2010 & 2000 & 2010 & 2000 & 2010 & 2000 & 2010 & 2000 & 2010 & 2000 & 2010 \\
\hline \multirow{2}{*}{ Megalópole } & 53,554 & 80,493 & 1.442 .598 & 1.415 .532 & 498,919 & 590,901 & 1.027 .944 & 1.284 .087 & 2.636 .923 & 3.105 .514 & 535,04 & 635,367 & 101,1057 & 159,3064 \\
\hline & $0,74 \%$ & $0,92 \%$ & $20,02 \%$ & $16,26 \%$ & $6,92 \%$ & $6,79 \%$ & $14,27 \%$ & $14,75 \%$ & $36,59 \%$ & $35,68 \%$ & $7,42 \%$ & $7,30 \%$ & $14,03 \%$ & $18,30 \%$ \\
\hline \multirow{2}{*}{$\begin{array}{l}\text { Grande } \\
\text { Metrópole }\end{array}$} & 31,378 & 38,726 & 452,192 & 450,299 & 328,299 & 407,006 & 825,26 & 1.008 .138 & 1.689 .303 & 1.993 .468 & 319,859 & 370,52 & 544,15 & 726,201 \\
\hline & $0,75 \%$ & $0,78 \%$ & $10,79 \%$ & $9,02 \%$ & $7,83 \%$ & $8,15 \%$ & $19,69 \%$ & $20,19 \%$ & $40,31 \%$ & $39,91 \%$ & $7,63 \%$ & $7,42 \%$ & $12,99 \%$ & $14,54 \%$ \\
\hline \multirow{2}{*}{ Metrópoles } & & & & & 96,672 & & 218,164 & 261,568 & 446,851 & 529,97 & 75,632 & 87,722 & 126,853 & 175,963 \\
\hline & $2,09 \%$ & $2,18 \%$ & $14,12 \%$ & $13,04 \%$ & $8,40 \%$ & $8,62 \%$ & $18,96 \%$ & $18,88 \%$ & $38,83 \%$ & $38,25 \%$ & $6,57 \%$ & $6,33 \%$ & $11,02 \%$ & $12,70 \%$ \\
\hline \multirow{2}{*}{$\begin{array}{l}\text { Grandes } \\
\text { Cidades }\end{array}$} & 12,937 & 12,517 & 72,357 & 67,761 & 43,01 & 40,647 & 90,566 & 84,244 & 200,321 & 170,577 & 32,485 & 26,562 & 44,827 & 51,718 \\
\hline & $2,61 \%$ & $2,76 \%$ & $14,57 \%$ & $14,92 \%$ & $8,66 \%$ & $8,95 \%$ & $18,24 \%$ & $18,55 \%$ & $40,35 \%$ & $37,57 \%$ & $6,54 \%$ & $5,85 \%$ & $9,03 \%$ & $11,39 \%$ \\
\hline \multirow{2}{*}{$\begin{array}{l}\text { Cidades Médias } \\
\text { de Longo Alcance }\end{array}$} & 10,349 & 9,239 & 38,423 & 23,77 & 17,495 & 13,267 & 38,836 & 27,642 & 82,801 & 57,374 & 12,145 & 8,215 & 18,034 & 13,106 \\
\hline & $4,75 \%$ & $6,05 \%$ & $17,62 \%$ & $15,58 \%$ & $8,02 \%$ & $8,69 \%$ & $17,81 \%$ & $18,11 \%$ & $37,97 \%$ & $37,59 \%$ & $5,57 \%$ & $5,38 \%$ & $8,27 \%$ & $8,59 \%$ \\
\hline \multirow{2}{*}{$\begin{array}{l}\text { Cidades Médias } \\
\text { de Médio Alcance }\end{array}$} & 5,746 & 5,017 & 9,26 & 6,972 & 4,845 & 4,054 & 9,844 & 7,339 & 22,8 & 16,619 & 3,248 & 2,216 & 3,787 & 3,119 \\
\hline & $9,65 \%$ & $11,07 \%$ & $15,56 \%$ & $15,38 \%$ & $8,14 \%$ & $8,94 \%$ & $16,54 \%$ & $16,19 \%$ & $38,30 \%$ & $36,66 \%$ & $5,46 \%$ & $4,89 \%$ & $6,36 \%$ & $6,88 \%$ \\
\hline \multirow{2}{*}{$\begin{array}{l}\text { Cidades Médias } \\
\text { de Curto Alcance }\end{array}$} & 4,442 & 2,902 & 3,174 & 2,793 & 1,676 & 1,328 & 3,243 & 2,374 & 7,771 & 5,297 & 1 & 675 & 1,041 & 810 \\
\hline & $19,88 \%$ & $17,94 \%$ & $14,21 \%$ & $17,26 \%$ & $7,50 \%$ & $8,21 \%$ & $14,51 \%$ & $14,67 \%$ & $34,77 \%$ & $32,74 \%$ & $4,48 \%$ & $4,17 \%$ & $4,66 \%$ & $5,01 \%$ \\
\hline \multirow{2}{*}{$\begin{array}{l}\text { Pequenas } \\
\text { Cidades I }\end{array}$} & 5,736 & 6,746 & 576 & 908 & 383 & 820 & 1,003 & 1,805 & 1,713 & 3,294 & 235 & 406 & 151 & 355 \\
\hline & $58,55 \%$ & $47,06 \%$ & $5,88 \%$ & $6,34 \%$ & $3,91 \%$ & $5,72 \%$ & $10,24 \%$ & $12,59 \%$ & $17,49 \%$ & $22,98 \%$ & $2,40 \%$ & $2,83 \%$ & $1,54 \%$ & $2,48 \%$ \\
\hline \multirow{2}{*}{$\begin{array}{l}\text { Pequenas } \\
\text { Cidades II }\end{array}$} & 2,255 & 3174 & 1274 & 120 & 662 & 403 & 1,239 & 933 & 2765 & 1,454 & 368 & 180 & 331 & 160 \\
\hline & $25,07 \%$ & $49,46 \%$ & $15,28 \%$ & $5,98 \%$ & $7,36 \%$ & $5,74 \%$ & $13,77 \%$ & $13,28 \%$ & $30,74 \%$ & $20,71 \%$ & $4,09 \%$ & $2,56 \%$ & $3,68 \%$ & $2,27 \%$ \\
\hline \multirow{2}{*}{$\begin{array}{l}\text { Núcleos } \\
\text { Urbanos I }\end{array}$} & 2,207 & 1,654 & 288 & 456 & 186 & & 492 & 612 & 747 & 949 & 105 & 120 & 67 & 115 \\
\hline & $53,95 \%$ & $39,59 \%$ & $7,04 \%$ & $10,93 \%$ & $4,54 \%$ & $6,51 \%$ & $12,02 \%$ & $14,65 \%$ & $18,26 \%$ & $22,71 \%$ & $2,57 \%$ & $2,87 \%$ & $1,63 \%$ & $2,75 \%$ \\
\hline \multirow{2}{*}{$\begin{array}{l}\text { Núcleos } \\
\text { Urbanos II }\end{array}$} & 771 & 678 & 195 & 224 & 108 & 123 & 265 & 316 & 386 & 404 & 55 & 50 & 36 & 47 \\
\hline & $42,46 \%$ & $36,82 \%$ & $10,74 \%$ & $12,17 \%$ & $5,92 \%$ & $6,70 \%$ & $14,60 \%$ & $17,14 \%$ & $21,27 \%$ & $21,91 \%$ & $3,01 \%$ & $2,70 \%$ & $2,00 \%$ & $2,56 \%$ \\
\hline \multirow[t]{2}{*}{ GERAL } & 2,322 & 2,36 & 1,678 & 2027 & 875 & 1206 & 1,924 & 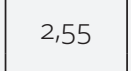 & 4008 & 5,125 & 639 & 787 & 885 & 1,384 \\
\hline & $18,77 \%$ & $15,28 \%$ & $13,56 \%$ & $13,15 \%$ & $7,08 \%$ & $7,81 \%$ & $15,55 \%$ & $16,51 \%$ & $32,72 \%$ & $33,19 \%$ & $5,17 \%$ & $5,10 \%$ & $7,15 \%$ & $8,96 \%$ \\
\hline
\end{tabular}

\section{Apêndice B}

Média de trabalhadores por atividades econômicas por hierarquias (2000 e 2010).

Fonte: Elaboração própria com base nos resultados da PAM. 


\section{Clauber Eduardo Marchezan Scherer}

Doutor em Economia pela UFMG/Cedeplar; assessor parlamentar na Câmara Municipal de Porto Alegre.

Email: clauberscherer@yahoo.com.br

ORCID: 0000-0003-0596-7053

\section{Pedro Vasconcelos Maia do Amaral}

Doutor em Economia pela University of Cambridge, professor adjunto da UFMG/Cedeplar.

Email: pedrovma@cedeplar.ufmg.br

ORCID: 0000-0002-2505-035X

Submissão: 17 de novembro de 2018

Aprovação: 30 de julho de 2019

Como citar: SCHERER, C. E. M.; AMARAL, P. V. M. do. O espaço e o lugar das cidades médias na rede urbana brasileira. Revista brasileira de estudos urbanos e regionais. V.22, E202001, 2020.

DOI: 10.22296/2317-1529.RBEUR.202001

Artigo licenciado sob Licença Creative Commons (CC-BY) 